\title{
POPULARIZAÇÃO DA TAXONOMIA DE SOLO: VOCABULÁRIO MÍNIMO E ASPECTOS SÓCIO-ECONÔMICOS NO CONTEXTO DO ENSINO FUNDAMENTAL, EM SÃO MIGUEL, ESPERANÇA (PB) $)^{(1)}$
}

\author{
Adriana Araújo Diniz ${ }^{(2)}$, Rui Bezerra Batista(3) \\ \& Roseilton Fernandes dos Santos ${ }^{(4)}$
}

\begin{abstract}
RESUMO
Este estudo objetivou construir uma proposta pedagógica com alunos de nível fundamental na comunidade de São Miguel, Esperança (PB). Procurou-se despertar o interesse dos estudantes para a importância do solo em suas vidas, bem como adequar a terminologia usada na pedologia à linguagem cotidiana dos alunos. Seguiu-se como método a abordagem paulofreireana na qual se considera que o contexto da escola extrapola o da sala de aula, devendo envolver o máximo de pessoas da comunidade. Assim, procurou-se levantar informações quanto à renda familiar, moradia, número de irmãos e irmãs, atividade princípal do responsável pela família, etc. Deste levantamento, extraiu-se, também, o vocabulário mínimo, com palavras e expressões geradoras que sintetizam o universo de conhecimento em São Miguel. Os resultados denotaram a dureza do cotidiano e uma educação repressiva diante da indomabilidade dos filhos. Observou-se que elementos pedagógicos presentes no vocabulário mínimo podem facilitar a popularização do saber pedológico no ensino fundamental. 0 vocabulário mínimo promoveu uma melhor comunicação durante as aulas entre educadores e educandos, bem como permitiu a construção de conceitos para as ordens de solos mais representativas da região: Neossolos e Argissolos. A construção de monólitos de solos constituiu importante recurso auxiliar nas aulas expositivas e dialógicas, despertando nas crianças maior interesse para o tema solo e meio ambiente.
\end{abstract}

Termos de indexação: pedologia, linguagem, taxonomia de solo.

(1) Trabalho apresentado no XXVIII Congresso Brasileiro de Ciência do Solo, Londrina (PR), 01 a 06 de julho de 2001. Recebido para publicação em dezembro de 2001 e aprovado em fevereiro de 2005.

(2) Estudante do Curso de Agronomia do Centro de Ciências Agrárias Universidade Federal da Paraíba - CCA/UFPB. Campus III, CEP 58397-000 Areia (PB). Bolsista PIBIC/CNPq.

(3) Professor do DSER/CCA/UFPB. E-mail: rui_bezerra@uol.com.br

(4) Doutorando em Solos e Nutrição de Plantas, Departamento de Solos, Universidade Federal de Viçosa - UFV. Campus Universitário, CEP 36570-000 Viçosa (MG). E-mail: rfsolos@bol.com.br 


\title{
SUMMARY: POPULARIZATION OF SOIL TAXONOMY: MINIMUM VOCABULARY AND SOCIOECONOMICAL ASPECTS IN THE CONTEXT OF AN ELEMENTARY SCHOOL IN SÃO MIGUEL, ESPERANÇA COUNTY (PARAIBA)
}

\begin{abstract}
This work aimed at creating an educational project with elementary school students from the São Miguel community in Esperança county, state of Paraiba, Brazil. We encouraged the children to think about the importance of soil in their life, and also tried to use a pedologic terminology adapted to the students' everyday language. The applied methodol ogy fol lowed Paulo Freire's approach, which extrapolates the school context from the classroom and tries to reach out for as many peopl ein the community as possi ble. Thus, information was collected on the families income, housing type, number of brothers and sisters, main occupation of thefamily head, etc. A minimum vocabulary, with words and expressions that synthesizeSão Miguel's overall knowl edge, was extracted from this initial survey. Results reflect the hard lifeand a repressive education when it comes to children's rebel liousness. Pedagogic edements present in themi nimum vocabulary suggest that pedol ogic knowledgecould bepopularized in elementary schools. Themi ni mum vocabulary promoted a better communication between educators and students during classes. It al so favored the construction of concepts for the most representativesoils types - Entisols and UItisols. The construction of soil monol iths represented an important part of theexpository and dial ogue classes, arousing theinterest of children for the soil and environment subjects.

Index terms: pedology, language, soil taxonomy.
\end{abstract}

\section{NTRODUÇÃO}

O ensino de sol os tem sido objeto de importantes trabalhos, como o de Braida (1997). No entanto, muitos deles são ainda voltados para uma pequena fatia da sociedade: a que chega à Universidade, representada por estudantes de cursos de agronomia, ciências florestais, geografia, etc. Pouca preocupação, pelo menos relativamente, é dispensada ao ensino fundamental e médio. Mais grave, ainda, éa situação do ensino da classificação de sol os, fragmentação queéfamiliar a uma pequena parcela dos que atuam na ciência do solo.

Segundo Reichardt (1988), não seria exagerado recomendar que, mesmo no ensino fundamental e médio, oestudo do sol o seja introduzi do com um nível razoável de detalhe. Some-se o nível médio de escolaridade da população brasileira ao fato de o processo de desenvolvimento brasileiro ter sido moldado a partir da visão e dos interesses da elite dominante, tendo sido o sistema de ensino, pesquisa e extensão rural direcionado para atender a essa elite, frente a desafios de desenvolvimento por ela estabel ecida (J esus, 1998).

Para Salet (1997), são três as correntes explicativas, que mais se destacaram neste século, do processo de formação de conhecimento: apriorismo, empirismo associacionista e teoria do construtivismo. A epistemologia do al uno do curso deagronomia e- por extensão- das ciências agrárias como um todo, éa do empirismo. Urgea necessidade de um contundente esforço para a popularização do saber pedológico, a exemplo do que propôs Lopes (1988) para a geologia.

Se se considerar que ensinar não é transferir conhecimentos, que ensinar é uma característica humana equenão há docência sem discência (Freire, 1996), podem-se encontrar el ementos que favoreçam o rompimento da práxis vigente. Aliado ao enfoque problematizador de aspectos contextuais relacionados com sol os, o ensino da pedol ogia poderá atingir outros segmentos da sociedade.

O objetivo deste estudo foi construir uma proposta pedagógica com estudantes de nível fundamental na comunidade de São Miguel, Esperança (PB), procurando integrar a taxonomia de solos aos aspectos sócio-econômicos de suas famílias e despertar o interesse para a importância do solo em suas vidas.

\section{FUDAME NTAÇÃO TEÓRICA}

O sol o tem deser visto como patrimônio de todos. No entanto, al guns não percebem essa importância, talvez por não saberem exatamente o seu significado ou, até mesmo, por não terem o conhecimento do que vem a ser solo (Reichardt, 1988). É necessária maior atenção em relação ao estudo do solo, pois a preservação do meio ambiente depende de uma consciência ecológica e a formação desta requer educação. Para que isso ocorra, é necessário que haja cidadania, ou seja, consciência de direitos e deveres (Gadotti, 2000). 
A obra de Feitosa (1996) trata de práticas importantes para a educação ambiental no ensino fundamental (efeito estufa, chuva ácida, buraco na camada de ozônio, etc.) de forma abrangente; entretanto, oenfoque poderia ser mais bem apreendido pelos estudantes se forem selecionados exemplos mais próximos do cotidiano da própria escola.

Segundo Lacki (2000), os governos deveriam estabelecer model os integrados de educação como estratégia, em vez dos atuais, baseados na memorização de datas etemas longínquos, abstratos edistantes dos problemas cotidianos. Ainda, em médio prazo, incluir nas escolas de ensino fundamental em zonas rurais temas úteis e práticos (sobre produção agrícola, organização comunitária, associativismo, administração rural, educação familiar, etc.); nas escolas fundamentais, os conteúdos educativos deveriam responder às necessidades de vida e de trabal ho imperantes no campo.

Um dos pressupostos do método Paulo F reireéa idéia de que ninguém educa ninguém e ninguém se educa sozinho. A educação deve ser um ato col etivo, solidário, não podendo ser imposta. Educar é uma tarefa de trocas entre pessoas. Segundo Paulo Freire, não há educadores nem educandos puros (Brandão, 1981). No entanto, segundo Lima (1999), os educadores, em sua maioria, fundamentam-sena idéia de que é possível ensinar aos outros por meio de explicação oral. Convencidos disto, concentram todos os seus esfor ços no sentido de condensar seus conhecimentos e de expô-los de forma lógica e clara. Cabe ao educador, nessa percepção, decidir acerca da ordem, do ritmo e da profundidade a ser dada ao ensino. Quanto ao educando, cabe a ele ser dócil, atento e submisso à autoridade do educador.

Assim acontece também com o processo extensionista destinado ao homem do campo. Essa maneira de agir e pensar aparece como a estratégia que caracteriza o que F reire (1987) denominou de educação bancária. Para Freire(1996), énecessário ter a convicção de que mudar, embora difícil, é possível, enquanto Gadotti (2000) crê que mudar a maneira de pensar é fundamental para a busca de uma visão mais global do mundo.

A pedagogia não está mais centrada na didática, em como ensinar, mas na ética e na filosofia. O professor não é mais o que sabe e o aluno, o que aprende. Ambos, em sessões de trabal ho, aprendem eensinam com oquejuntos descobrem (Gadotti, 2000). Ensinar não é transferir conhecimento. Ensinar é uma maneira defacilitar a aprendizagem, defornecer conhecimentos necessários à vida (Freire, 1996).

U ma contraposição à educação bancária é o método Paulo Freire. Simplificadamente, trata-se (o método) de uma pesquisa simples que tem como objetivo a obtenção dos vocábulos mais usados pela população a ser alfabetizada (as palavras e expressões geradoras), apontando regras de fazer, mas nunca impondo formas sobre como o fazer
(Brandão, 1981). O método pode ser utilizado para outras situações, além da alfabetização. Ele se reconstrói a cada vez que é coletivamente usado, dentro de um círculo de cultura de educadores - e educandos, envolvendo um máximo de pessoas da comunidade (Brandão, 1981).

Deacordo com Silva (2000), oSistema Brasileiro de Classificação de Solos (E mbrapa, 1999) fornece um conjunto de informações pedológi cas preciosas e apresenta um inexplorado potencial para o monitoramento e aval iação de qual idade de solo. 0 ensino da pedologia pode agregar-se, também, ao que Gadotti (2000) chamou de Ecopedagogia, definida como uma pedagogia voltada para a promoção da aprendizagem no sentido das coisas a partir da vida cotidiana.

\section{MATERIAL E MÉTODOS}

\section{Aspectos gerais}

São Miguel é um distrito do município de Esperança, localizado a $7^{\circ} 01^{\prime} 07^{\prime \prime}$ de longitudeSul e $35^{\circ} 51$ ' 26 " de latitude Oeste (Mobral, 1985), e inserido na microrregião 166 do estado da Paraíba que faz parte da mesorregião da Borborema 042 (IBGE, 1989). E sta região engl oba os municípios de Areial, Esperança, Montadas e São Sebastião de Lagoa de Roça, sendo Esperança o maior em extensão geográfica, com 139 km² (M obral, 1985).

Para a identificação das microrregiões, foram usados dois indicadores básicos: a estrutura da produção primária ea interação espacial. O espaço microrregional foi identificado pela interação entre as áreas de produção e locais de beneficiamento e pela distribuição de bens e serviços de consumo freqüentes (IBGE, 1989). Na identificação de uma mesorregião, foram utilizados os seguintes itens: 0 processo social, como determinante; o quadro natural, como condicionante, e a rede de comunicação e de lugares, como el emento da articulação espacial (IBGE, 1989).

Pedologicamente, encontram-se na microrregião 166 as seguintes unidades de mapeamento: REd, PE 13, Re6 e Re18. São mostradas no quadro 1 as mais representativas do município de Esperança (Brasil, 1972).

Para delimitação das unidades de mapeamento, recorreu-se ao Levantamento de solos do estado da Paraíba (Brasil, 1972), texto explicativo e mapa de sol os. Para estimativa da ordem deabrangência das unidades, os limites geográficos da microrregião 166, com os respectivos municípios, foram superpostos ao mapa pedológico. Os mapas usados eram de mesmas escalas, aproximadamente 1:1.000.000. As unidades de solos, compiladas de Brasil (1972), foram mantidas em sua identificação original. 
Quadro 1. Principais unidades de mapeamento no município de Esperança (PB)

\begin{tabular}{|c|c|c|}
\hline & \multicolumn{2}{|r|}{ Unidade de mapeamento } \\
\hline & Regossolo distrófico (Red) & Podzólico Vermelho-Amarelo (PEI3) \\
\hline $\begin{array}{l}\text { Extensão total } \\
\text { da classe de solo } \\
\text { no estado da } \\
\text { Paraíba }\end{array}$ & $610 \mathrm{~km}^{2}$ & $440 \mathrm{~km}^{2}$ \\
\hline $\begin{array}{l}\text { \% em relação à } \\
\text { área total do } \\
\text { estado da } \\
\text { Paraíba }\end{array}$ & 1,08 & 0,78 \\
\hline Constituição & $\begin{array}{l}\text { Unidade simples constituída } \\
\text { de Regossolo distrófico fase } \\
\text { floresta caducifólia relevo } \\
\text { suave ondulado. }\end{array}$ & $\begin{array}{l}\text { Associação constituída de Podzólico Vermel ho-Amarelo } \\
\text { E quivalente eutrófico com A proeminente textura argil osa } \\
\text { fase floresta subcaducifólia relevo ondulado e forte } \\
\text { ondulado e Solos Litólicos eutróficos com A proeminente } \\
\text { textura média fase pedregosa e rochosa floresta } \\
\text { subcaducifólia rel evo forte ondulado e montanhoso } \\
\text { substrato gnaisse e granito. O primeiro componente } \\
\text { apresenta-se com notável dominância sobre o segundo, } \\
\text { sendo de } 80 \text { e } 20 \% \text {, respectivamente, suas parcelas na } \\
\text { área da associação. Os trechos mais acidentados da área } \\
\text { relacionam-se com a unidade de Solos Litólicos eutróficos } \\
\text { com A proeminente textura média. }\end{array}$ \\
\hline $\begin{array}{l}\text { Principais } \\
\text { inclusões }\end{array}$ & $\begin{array}{l}\text { Podzólico Vermel ho-Amarelo } \\
\text { Equivalente eutrófico abrupto } \\
\text { textura média fase floresta } \\
\text { caducifólia suave ondulado e } \\
\text { ondulado; Sol os Litólicos } \\
\text { eutróficos com A fraco textura } \\
\text { arenosa e, ou, média fase } \\
\text { pedregosa caatinga } \\
\text { hipoxerófila rel evo suave } \\
\text { ondulado substrato gnaisse e } \\
\text { granito; Regossolo eutrófico } \\
\text { com fragipan fase floresta } \\
\text { caducifólia relevo suave } \\
\text { ondulado; e Afloramentos de } \\
\text { rocha }\end{array}$ & $\begin{array}{l}\text { Terra Roxa Estruturada eutrófica fase floresta } \\
\text { subcaducifólia relevo forte ondulado; Regossolo }\end{array}$ \\
\hline
\end{tabular}

Fonte: Brasil (1972).

\section{Levantamento de aspectos contextuais}

No presente trabalho, seguindo a abordagem paul ofreiriana, o contexto da escola extrapola o da sala de aula. Assim, procurou-se levantar informações quanto à renda familiar, moradia, número de irmãos e irmãs, atividade principal do responsável pela família, se há saneamento básico em suas casas, de onde bebem água, se há fossa séptica, onde evacuam, quais as dificuldades na escavação das fossas. Se os pais são anal fabetos ou não. Foram consideradas na análise 30 casas e, conforme Rocha (1997), o número de entrevistas atingiu 23,04. As entrevistas com pais e alunos constaram de duas, uma no início e outra no final do ano letivo de 2000, enquanto o contato com al unos durou todo o ano letivo. Participaram desse contato uma professora do ensino fundamental ( 3 a série) e os coordenadores da pesquisa (estudante de iniciação científica, professor universitário eestudante de pósgraduação). Os entrevistados foram identificados pelo sexo, idade e série escolar.

Deste levantamento, extraiu-se, também, o vocabulário mínimo, a partir do qual novas etapas do presente trabalho foram construídas. Evitou-se o termo questionário, preferindo-se memória da dialogicidade (Quadro 2) e, na confecção do roteiro (Quadro 3) para esses diálogos, recorreu-se a Brandão (1981) e Kiehl (1979).

O número de entrevistas para dar acurácia à pesquisa foi determinado conforme Rocha (1997). A fórmula a seguir permitiu estimar onúmero devisitas, em que: $n=$ número de visitas a serem feitas pelos pesquisadores; 3,841=val or tabelado proveniente do qui-quadrado; 0,25 = variância máxima para um desvio-padrão de 0,$5 ; 0,1=$ erro (10 \%); $\mathrm{N}=$ número total de casas da unidade considerada: 
Quadro 2. Sumário dos questionários aplicados à comunidade (memórias da dialogicidade)

Atividade familiar principal

Agricultura
Comércio
Outros
Água encanada
Possui cisterna
Número de famílias que evacuam a céu aberto
Escoamento sanitário
- Rede de esgoto
- Fossa domiciliar
Origem da água para consumo doméstico
- Companhia de Água e Esgoto da Paraíba (CAGEPA)
- Açudes

Número de famílias

\section{Quadro 3. R oteiro de uma das aulas lecionadas a estudantes do ensino fundamental (terceira série) em São Miguel, E sperança (PB)}

\section{Solos}

1.1. Definição de solos

1.1.1. Definição de solos através do vocabulário mínimo

1.2. A origem do solo

1.3. Os constituintes do solo

1.4. A importância dos solos em suas vidas

1.5. Falar sobre os horizontes do solo

2. Ilustração com monólitos

2.1. Definição de monólitos

2.2. Chamar atenção quanto aos nomes dos solos

3. Pintura

3.1. Distribuir fol has de papel para os alunos pintarem a seu critério

3.2. Entregar aos alunos ilustrações de perfis de solos para os alunos pintarem

3.3. Relacionar a cor da pintura à cor do solo

3.4. Fazer indagações com relação à pintura

3.5. Recolher os desenhos e pendurá-los em varais

\section{Porosidade}

4.1. Definição de porosidade

4.2. Categorias: macro e microporosidade

4.2.1. Macro - menor retenção de água, maior velocidade de infiltração (solos arenosos)

4.2.2. Micro - maior retenção de água, menor velocidade de infiltração (solos argilosos)

4.3. Importância da matéria orgânica para a porosidade dos solos

4.4. Exemplificar porosidade com bolas de gude

4.5. Resultados (indagações por parte dos alunos)

4.6. Comentários dos resultados

4.7. Falar sobre as verminoses que podem existir nos espaços vazios dos solos

4.8. Importância de se fazer exames de fezes (desfecho motivador)

5. Avaliação escrita e, ou, oral dos alunos

6. Material necessário: Monólitos dos perfis representativos da comunidade; barro para modelar; água; depósitos plásticos; varal; prendedores, pincéis; folhas de ofício; bolas de gude; ficha de avaliação; recipientes plásticos para coleta de fezes que serão encaminhadas para análise parasitológica.

$\mathrm{n}=3,841 \cdot \mathrm{N} \cdot 0,25 /\left\{(0,1)^{2} \cdot(\mathrm{N}-1)+3,841 \cdot 0,25\right\}$

Os conceitos referentes a sol os foram compilados e, ou, adaptados de Brasil (1972), Embrapa (1999) e
Lepsch (1993). Os monólitos e outras práticas, como pintura usando material solo, foram inspirados em Cardoso \& Fernandes (1997). 
Para reclassificação pedológica, recorreu-se à identificação dos perfis de solos que foram empregados na classificação original de Brasil (1972). Feita a identificação, os perfis representativos de cada unidade taxonômica foram redassificados (Quadro 4), segundo o Sistema Brasileiro de Classificação de Solos (Embrapa, 1999).

\section{RESULTADOS E DISCUSSÃO}

\section{Construção de conceitos para as classes desolos}

\section{Definições para crianças (utilizando o vocabulário mínimo registrado)}

Os Neossolos são aquelas terras onde seus pais plantam batatinha, são esbranquiçadas e não possuem barro, não sendo possível mol dar, fazer fios ou bonequinhos. Os N eossolos se dividem em Neossol os Litólicos, Neossol os Regolíticos, Neossolos Flúvicos e Neossolos Quartzarênicos, que são subordens. Essas, por sua vez, diferem quanto à quantidade etamanho das pedras e grãos de areias expostos na superfície do solo. Vejamos o exemplo dos Neossolos Quartzarênicos, eles são terras esbranquiçadas que não possuem barro, não sendo possível moldar, pois apresentam muita areia, que são aquelas terras encontradas nas margens dos riachos. O solo ou terra, como é mais conhecida, é dividida em areia, silte e argila, esta divisão está apresentada do maior para o menor tamanho de partículas. A areia divide-seainda em areia grossa e areia fina e mostram em sua constituição cerca de $95 \%$ de quartzo, que é um mineral resistente à quebra (intemperismo). Para a agricultura, esses solos são considerados pobres. Por exemplo: num roçado em um N eossolo Quartzarênico, o agricultor sóconsegue uma boa produção seadubar a terra. Caso contrário o que ganhar não dará nem para comer.
Por outro Iado, os Argissolos são terras avermel hadas constituídas por material mais ou menos macio, chamado popularmente de barro, que gruda no sapato e é utilizado para moldar e para fazer bonequinhos. O solo é como um bolo, vamos imaginar um bolo de aniversário que tem várias camadas, uma em cima da outra, o sol o também tem as suas camadas denominadas horizontes, e o barro fica logo abaixo do primeiro horizonte da terra que é chamado de horizonte $A$, que, neste tipo de solo, é rico em areia. Esse solo é mais rico em elementos essenciais ao mel hor desenvolvimento das plantas, mas, comumente, não é nel e que nossos pais e mães cultivam batatinha. Como foi dito, o Argissol o tem uma fatia (horizonte) que é mais rica em barro (argila). A parte de cima da fatia é composta de terra arenosa eé mais susceptível à ação das chuvas, causando estragos, como formação de valas e buracos, em um processo chamado de erosão do sol o. $\mathrm{N}$ os terrenos enladeirados, quando se planta de morro abaixo, esse processo se intensifica e com a não-adoção de medidas preventivas de controle, como plantar no atravessado (em nível) em vez de plantar no comprido (morro abaixo), esse buraco poderá crescer demais e formar voçorocas, que é o estádio mais avançado da erosão do solo. Os Argissolos são divididos nas seguintes subordens: Argissolos Acinzentados, Argissolos Amarelos, Argissolos Vermelho-Amarelos e Argissolos Vermelhos.

\section{Vocabulário mínimo e aspectos sócio-econômi- $\cos$}

As palavras geradoras compiladas registram o contexto dos estudantes amostrados. Elas foram agrupadas em universos relativamente homogêneos (Quadro 5).

PauloFreire (Brandão, 1981) chamava a atenção para o fato de ter a democratização da cultura de partir do que somos e do que pensamos. Provavelmente, as crianças aqui consideradas

Quadro 4. Reclassificação pedológica das classes de solos das principais unidades de mapeamento no município de Esperança (PB)

Unidade de mapeamento

\begin{tabular}{|c|c|c|c|}
\hline \multirow[t]{2}{*}{ Hierarquia } & \multicolumn{2}{|c|}{ Podzólico Vermelho-Amarelo (PE 13) } & \multirow{2}{*}{$\begin{array}{c}\text { Regossolo distrófico (Red) } \\
\text { Perfil } 63\end{array}$} \\
\hline & Perfil 59 & Perfil 22 & \\
\hline Ordem & Argissolo & Neossolo & Neossolo \\
\hline Sub ordem & Argissolo Vermelho & N eossolo Litólico & Neossolo Quartzarênico \\
\hline Grande grupo & Argissolo Vermel ho eutrófico & N eossolo Litólico eutrófico & Neossolo Quartzarênico Órtico \\
\hline Sub grupo & $\begin{array}{l}\text { Argissolo Vermel ho eutrófico } \\
\text { típico }\end{array}$ & $\begin{array}{l}\text { Neossolo Litólico eutrófico } \\
\text { típico }\end{array}$ & $\begin{array}{l}\text { Obs: Os dados dessa classe } \\
\text { permitiram a reclassificação }\end{array}$ \\
\hline
\end{tabular}


pensam com, ou se expressam, usando estas palavras. E estas refletem um mundopredominantemente agrícola. Outras nuances são apresentadas quando são reconstruídas as expressões geradoras registradas (Quadro 6). A maioria das expressões denota a pobreza da comunidade. Outras revelam uma educação repressiva (3), diante da indomabilidade dos filhos e das filhas (2). A dureza do cotidiano $(4,7,11)$ expressa-se involuntariamente. Todavia, a fé, a expectativa de dias melhores e de melhores rendas está associada à educação, ou à escola atribui-se um papel sobremaneira importante para a sobrevivência, apesar de a sala de aula não parecer motivadora (10) diante das dificuldades do cotidiano. Como esses, existem outros elementos pedagógi cos no vocabulário mínimo, não explorados nessa etapa da pesquisa, que facilitarão a popularização do saber pedológico para essas crianças. Por exemplo: que solos merecerão maior cuidado no tocante à poluição e contaminação de aqüíferos? Ou, ainda, como manejar e conservar esses solos de forma sustentável, considerando potencialidades e deficiências inerentes a cada um deles?

\section{CONSIDE RAÇÕES FINAIS}

1. As palavras e expressões geradoras registradas em São Miguel foram importantíssimas ao processo de ensino eaprendizagem, contribuindo para a maior interação entre educador e educando durante os ciclos de cultura. Foram selecionados os solos mais representativos da região, Neossolos e Argissolos, e, com base nesse conhecimento, discutiram-se as diferenças e práticas de manejo importantes para a conservação do solo e para a manutenção das produções em São Miguel.

2. Os monólitos de sol os constituíram importante recurso auxiliar às aulas expositivo-dialógicas. Serviram para mostrar que os solos são diferentes um dos outros e também apontar características básicas nessa diferenciação, atentando para os diferentes horizontes de solo, as diferentes tonalidades de cores e os seus nomes. Desse contato foi sugerido que se destinasse um espaço na própria escola para construção de um museu de solos.

3. A construção de conceitos para as classes de sol os Neossol os eArgissolos, com base novocabulário

\section{Quadro 5. Palavras que sintetizam o vocabulário mínimo do universo amostrado em São Miguel, município} de Esperança (PB)

\begin{tabular}{clc}
\hline $\begin{array}{c}\text { Divisão por grupo } \\
\text { de palavras }\end{array}$ & Palavras geradoras & $\begin{array}{c}\text { Número de } \\
\text { ocorrências }\end{array}$ \\
\hline Grupo 1 & $\begin{array}{l}\text { Agricultura, plantar, roçado, pedras, agricultor, areia, terra, barro, } \\
\text { piçarro, enxada, carrapicho. }\end{array}$ & $20-30$ \\
Grupo 2 & Batata, feijão, milho, cebola, jerimum, fava. & $15-20$ \\
Grupo 3 & Comerciante, feirante, aposentadoria. & $12-15$ \\
Grupo 4 & $\begin{array}{l}\text { Invocada, palha, buraco, tamborete, sufoco, gorro, polia, cabresto, } \\
\text { esperança, estudar, bagunça, pobre, cisterna, amojando. }\end{array}$ & $10-12$ \\
\hline
\end{tabular}

Quadro 6. Expressões geradoras que sintetizam o vocabulário mínimo do universo amostrado em São Miguel, município de Esperança (PB)

\begin{tabular}{clc}
\hline Divisão & \multicolumn{1}{c}{ Expressões geradoras } & Número total de ocorrências \\
\hline$(1)$ & Herança de pobre é o estudo. & 23 \\
$(2)$ & A mãe sabe os filhos que tem. & 20 \\
$(3)$ & Botar cabresto na gente. & 15 \\
$(4)$ & Pegar no cabo da enxada e ir para a luta. & 20 \\
$(5)$ & Não se pode ficar esperando Deus botar o pão na boca. & 10 \\
$(6)$ & Só estudando é que se consegue algo. & 23 \\
$(7)$ & O que se ganha não dá nem para comer. & 23 \\
$(8)$ & Estudar é a esperança de um futuro melhor. & 23 \\
$(9)$ & Podre de grude. & 10 \\
$(10)$ & É um sufoco para esses meninos irem para a escola. & 23 \\
$(11)$ & As coisas estão difíceis. & 20 \\
\hline
\end{tabular}


mínimo registrado, no primeiro nível categórico do Sistema Brasileiro de Classificação de Solos, e recorrendo-se a noções el ementares sobre atributos diagnósticos e horizontes diagnósticos, contribuiu para o maior interesse dos alunos durante as aulas para o tema solo e meio ambiente.

\section{AGRADECIMENTOS}

À Comunidade de São Miguel, pelo acol himento durante os ciclos de cultura. Ao Doutorando Ítalo Moraes Rocha Guedes (DPS/UFV), pela ajuda na tradução do resumo para a língua inglesa.

\section{LITE RATURA CITADA}

BRAIDA, J .A., ed. A fragmentação do conhecimento e sua superação epistemológica. Pato Branco: SBCS/CFET, 1997. 332p.

BRANDÃO, C.R. O ABC do método. In: BRANDÃO, C.R., ed. O que é Método Paulo Freire. São Paulo, Brasiliense, 1981. p.21-42. (Coleção Primeiros Passos, 38)

BRASIL. Ministério da Agricultura. I- Levantamento Exploratório-Reconhecimento de Solos do Estado da Paraíba. II - Interpretação para uso agrícola dos solos do Estado da Paraíba. Rio de J aneiro, 1972. 670p. (Boletim Técnico, 15; Série Pedologia, 8)

CARDOSO, I.M. \& FERNANDES, R.B.A. Paisagem de Viçosa. Viçosa, Universidade Federal de Viçosa, 1997. 20p.

EMPRESA BRASILEIRA DE PESQUISA AGROPECUÁRIAEMBRAPA - EMBRAPA. Sistema brasileiro de classificação de solos. Rio de J aneiro, Centro Nacional de Pesquisa de Solo, 1999. 412p.

FEITOSA. A.A.F.M.A. A educação ambiental na primeira fase do 1ograu. J oão Pessoa, Universidade Federal da Paraíba, 1996. 43p.

FREIRE, P. Ensinar nãoétransferir conhecimento. In: FREIRE, P., ed. Pedagogia da autonomia. 11.ed. São Paulo: Paz e Terra, 1996. p.52-101.
FREIRE, P. Pedagogia do oprimido. 17.ed. Rio de J aneiro, Paz e Terra, 1987. 184p.

FUNDAÇÃO INSTITUTO BRASILEIRO DE GEOGRAFIA E ESTATÍSTICA - FIBGE. Mesorregiões e Microrregiões Geográficas. Rio de J aneiro, 1989. v.38. p.4-13. (Boletim de Serviço, 1763)

GADOTTI, M. Pedagogia da terra. São Paulo, Peirópolis, 2000. 210p. (Brasil Cidadão)

J ESUS, E.L. Formação do profissional de ciências agrárias no limiar do século XXI: Desafios e perspectivas. R. Educ. Agric. Sup., 2:34-43, 1998.

KIEHL, E.J . Manual de edafologia. São Paulo, Agronômica Ceres, 1979. 262p.

LACKI, P. O que pedem os agricultores e o que podem os governos: R. Educ. Agric. Sup., 18:42-46, 2000.

LEPSCH, I.F. Solos: formação e conservação. 5.ed. São Paulo, Melhoramentos, 1993. 157p.

LIMA, H.V. Contribuição à regional ização do ensino de pedologia em microrregião afetada pela desertificação. Areia, Universidade Federal da Paraíba, 1999. 39p. (Trabalho de Conclusão de Graduação em Agronomia)

LOPES, M.M. Museu: uma perspectiva de educação em geol ogia. Campinas, Faculdade de E ducação/U NICAMP, 1988. 163p. (Tese de Mestrado)

MOVIMENTO BRASILEIRO DE ALFABETIZAÇÃO - MOBRAL. Livro do município de Esperança. J oão Pessoa, 1985. 118p.

REICHARDT, K. Porque estudar o solo? In: MONIZ, A.C., coord. A Responsabilidade social da ciência do solo. Campinas, Sociedade Brasileira de Ciência do Solo, 1988. p.75-78.

ROCHA, J.S.M. Amostragem. In: MANUAL de projetos ambientais. Santa Maria, Universidade Federal de Santa Maria. 1997. p.137-138.

SALET, R.L. A Epistemologia do aluno de agronomia. In: BRAIDA, J .A., ed. A fragmentação do conhecimento e sua superação epistemologica. Pato Branco, SBCS/CFET, 1997. p.297-301.

SILVA, R.B. Avaliação da qualidade do solo sob três agrossistemas do município de Areia, (PB). Areia, Universidade Federal da Paraíba, 2000. 69p. (Tese de Mestrado) 